\title{
La guerra en Colombia y la nueva normatividad penal
}

JOSÉ GUILLERMO EDUARDO FERRO TORRES

\section{RESUMEN}

Este artículo intenta acercarse a la problemática normativa del conflicto colombiano, arrancando de la presentación sintética del panorama histórico para proyectarse a la forma como el legislador integró las disposiciones universales sobre Derecho Internacional Humanitario al Código Penal, destacando los caracteres más salientes del Título sobre personas y bienes protegidos en el contexto respectivo.

\section{PALABRAS CLAVE}

Panorama histórico, conflicto, bloque constitucional, proporcionalidad, bienes jurídicos, sujetos activo y pasivo, modelos comportamentales.

\section{ABSTRACT}

This article tries to approach the to the group of problems of establish Rules over the Colombian conflict, beginning with the syntetic presentation of the historic panorama, proyecting it then to the form as how the Legislador integrated the universal disposition about Internacional Humanitarian Law to our Penal Code, emphazising the prominent characters of the Title about protected persons and goods in the respective context.

Profesor de la Facultad de Derecho de la Universidad Santo Tomás. 


\section{INDEX TERMS}

Historic panorama, conflict, constitutional block, proportionality, juridic goods, active and passive individuals, behaviour models.

Desde la Conquista, la contribución de los invasores españoles estuvo salpicada de actos de crueldad de toda naturaleza contra los aborígenes. Contra esa política se alzaron voces que aún siguen resonando a lo largo de nuestra historia. Desaprobando los abusos peninsulares, se pronunciaron los sacerdotes Francisco de Vitoria y Bartolomé de Las Casas. El primero en sus famosas Relecciones ${ }^{1}$ pasa revista a los grandes problemas suscitados por la Conquista del Nuevo Mundo y formula una doctrina que, como se ha dicho con acierto, tiene un valor teológico especulativo y práctico no sólo circunstancial, sino permanente. En aquellas décadas tan duras enseñó que no existirá paz entre los hombres hasta que se proscriba la violencia, y la justicia impere en las relaciones internacionales. El segundo no admite, a diferencia de Vitoria, título ninguno justo para guerrear y esclavizar, y menos para deponer a los caciques y califica de nulo o sin vaIor jurídico cuanto se ha hecho en las Indias².

En plena campaña libertadora, se producen órdenes que incitan a la guerra sin cuartel por parte tanto de los españoles como de los criollos. De ahí en adelante hemos vivido, pese a la independencia, en un clima fluctuante entre la guerra y la paz. Las guerras civiles del siglo antepasado fueron frecuentes y largas, hasta desembocar en los enfrentamientos que al principio se escudaron en desavenencias partidistas, hasta hoy, en donde la consolidación de las fuerzas guerrilleras en vastas regiones del país ha cancelado las opciones válidas para aspirar a la detención del derramamiento de sangre. Por desgracia, no se ha enfrentado el problema de manera uniforme, pues posiciones férreas consistentes en cerrar las puertas al diálogo son reemplazadas en cortos espacios temporales por concesiones y aflojamientos que sólo han conducido al paulatino endurecimiento de la tozudez mutua. Al expedirse la Constitución de 1991, se creyó que con la inclusión de normas que garantizaban un acercamiento a la supresión de las causas generadoras del desequilibrio social se restaban los argumentos que han servido de bandera a las fuerzas insurrectas para su accionar; por desgracia, ello no ha sido así.

De otra parte, Colombia ha adquirido con la comunidad internacional compromisos de toda naturaleza, incluidos los relacionados con el respeto a los Derechos Humanos en el sentido más ambicioso del término. Por eso, la expedición del Código Penal del 2000 incluyó dentro de su estructura las normas que, haciendo parte de convenios, tratados y pactos suscritos por nuestro país, debían tornarse aplicables. Precisamente, el título referido al desarrollo de "Personas y bienes protegidos por el DIH", como novedad que es, merece un estudio detenido, lo cual intentaremos plasmar en el presente trabajo.

\footnotetext{
Ver VITORIA, Francisco de. Relecciones sobre los indios y el derecho de guerra. Madrid: Espasa Calpe. 1972. pp. 31ss. LAS CASAS, Bartolomé de. Obras completas. Madrid: Alianza Editorial, 1990.

2 Ver MENÉNDEZ PIDAL, Ramón. EI P. Las Casas y Vitoria. Madrid: Espasa Calpe, 1996. pp. 9ss
} 


\section{BIENES JURÍDICOS TUTELADOS}

El desgastado, y muchas veces improductivo, método de indagar por el bien que la normatividad jurídico-penal pretende tutelar mediante el señalamiento de la denominación que preside el respectivo Título, muestra aquí una seria deficiencia, pues el enunciado, fuera de no servir como indicativo formal, remite al intérprete a escudriñar cada tipo para detectar, de una parte, la conexión directa con valores ya mostrados como dignos de protección por las indicaciones tradicionales, porque se alude en algunos casos a derechos reputados como fundamentales: vida, libertad, formación sexual, etc., así como escapados de esa catalogación y de otra a variaciones que constituyen alusiones a circunstancias que parecen caracterizar descripciones de conductas señaladas con independencia como punibles (v. gr. homicidio, lesiones, secuestro).

Sin embargo, gravitan dentro de ese universo jurídico tipos que no registran equivalencia comportamental con otro u otros en el Códigos, como perfidia, que podrían emparentarse con dispositivos anejos al tipo, a través de facetas que lo integran, tomando posición dentro de la riqueza de su estructura, como los medios que posibilitan la obtención del resultado punido, lo que puede asumir, por ejemplo, la posición de circunstancia de agravación o la producción de desequilibrios que anulen o minimicen las reacciones defensivas. Empero el esfuerzo por justificar el tratamiento aislado de las infracciones precisadas en el respectivo Título debe suspenderse con rapidez si se ha centrado la búsqueda de una explicación que asiente su solidez en la salvaguardia de un valor determinado. En cambio, surge con particular vigor el reconocimiento de la preponderancia de circunstancias que son las que le dan la dimensión aglutinante al elenco conformado por las figuras agrupadas bajo la común denominación de "personas y bienes protegidos por el Derecho Internacional Humanitario", las cuales fuerzan a hacer una doble indagación: la primera, acerca del lugar hacia donde apunta la denominación (que no es otra que la enmarcada en la presencia de una confrontación armada externa o interna, que asuma la magnitud prevista en las mediciones internacionales, en los convenios y tratados que facultan su invocación), puede ponerse en marcha, prescindiendo de la averiguación de su origen; esto es, del enjuiciamiento con respecto a licitud o ilicitud del conflicto. La segunda, atendiendo a los diferentes elementos particulares de cada uno de los tipos, los que iteran, de manera implícita o explícita, los mecanismos de aplicación que les confieren rango diferente al de sus similares conductuales y los incluyen dentro de un conjunto de donde es factible extraer homogeneidad por su causa.

Sabido es que en virtud de la expedición de la Constitución de 1991, las normas que integran los tratados y convenios suscritos por Colombia entran a formar parte del llamado bloque constitucional, lo cual significa que asumen el rango más alto dentro de la jerarquía jurídica a la par que con el resto de cánones establecidos en la Carta Política. Incluso, dada la naturaleza de la materia que se pretende plasmar con su auxilio, resulta indiferente que se asuma la posición de Parte, puesto que al interesar y comprometer a la humanidad entera, su cobertura y la obligación de acatar sus mandatos son universales. Otra cosa es que en el plano internacional las prohibiciones de realizar comportamientos reputados de cierta gravedad se establezcan sólo dentro de la óptica preceptiva; esto es, sin acompañamiento de una sanción determinada, en espera de que para conseguir su plena efectividad los Estados las incorporen a su normatividad interna, fijándoles ya penas determinadas con arreglo a las escalas sancionatorias que rigen en cada latitud, por lo que se ha sostenido que su aplicación es indirecta. 
Colombia, después de largos titubeos, decidió, con la expedición del Código Penal del 2000, destinar un apartado dentro del mismo a la contemplación de estas modalidades, para ponerse a tono con los compromisos internacionales y dar vida al principio de proporcionalidad, consistente en la fijación de un quantum punitivo determinado a las conductas que se tipifican en el Título respectivo, lo que valida la afirmación de que su aplicación es de carácter indirecto, en cuanto no operaría sino en la medida en que a nivel interno se demarquen sus secuelas retaliatorias concretas, aproximándose, de otro lado, al alcance de una especificidad que por primera vez se obtiene en nuestra legislación frente a esta temática, lo cual no significa que los graves atentados agrupados bajo la ambigua denominación atrás aludida escaparan del conocimiento de la justicia criminal, pues los mecanismos existentes los cubrían a satisfacción, en la medida en que han constituido transgresiones contra bienes jurídicos primordiales.

Para comprobarlo, basta con trasladarnos a las precedentes codificaciones y hacer el sencillo ejercicio de intentar encasillar en los marcos legales vigentes los comportamientos que constituyen la mayoría de los delineados en el Título examinado para obtener con rapidez la corroboración de tal aserto y descubrir que frente a las ejecutorias que implican una descripción cargada de lesividad (homicidio, lesiones, tortura, acceso carnal violento, etc.) que se erigen como reprochables en cualquier tiempo, y que pueden tildarse de comunes, emergen otras que, al ser consustanciales al surgimiento del conflicto, sólo pueden referirse a la naturaleza y devenir del enfrentamiento físico de fuerzas. Es lo que acontece con la utilización de medios y métodos de guerra ilícitos, p. ej. perfidia y actos de barbarie, lo que invita a sujetar los derechos objeto de reivindicación a dos apotegmas predicables de acontecimientos de guerra o de conflicto externo, aunque estas categorías de- ben replantearse: $1^{\circ}$. El mantenimiento a plenitud de la protección jurídica a quienes no participen en los mismos y sobre bienes de cierto rango y $2^{\circ}$. La regulación del despliegue de la fuerza, de acuerdo con parámetros definidos, temas de los que luego nos ocuparemos. Lo cual significa que no se crean, en efecto, nuevas categorías de bienes jurídicos, sino que el mantenimiento y cuidado de los tradicionales y universalizados, al reconocerse la presencia de una situación anormal (no queremos aludir a frecuencia, sino al hecho de que se legisla para épocas donde la paz es inestable), presidida por el despliegue de violencia, deben quedar regulados por la juridicidad.

Ya hemos dicho que se imponen dos precisiones acerca de los momentos relevantes en la cronología de los conflictos: el atinente a su génesis y el conectado con su dinámica como campos propicios de intervención regulatoria. En el ámbito del inicio de la confrontación, en la antigüedad, no se registran restricciones y mucho menos etiquetamientos morales que pudieran plasmarse en la deducción de consecuencias tangibles a nivel de responsabilización. La condición de vencedor, por sí sola, borra reatos y recriminaciones; es la suprema dadora de la razón. Frente a las oposiciones armadas internas, casi siempre, cuando buscaban el acceso al poder, entrañaban desconocimiento de la divinidad y eran reprimidas (si no triunfaban) con crueldad inaudita. En la actualidad, atendiendo a la primera acepción, entraríamos dentro de los dominios del llamado ius ad bello, respecto de las lides internacionales, que se hallan -así sea por pura retórica- prohibidas por el derecho de gentes. Hemos de reconocer que hasta ahora, lo que en teoría debe ser regulado por el Derecho, en la práctica dista mucho de serlo. En esa dirección, la Carta de las Naciones Unidas en su art. $2^{\circ}$ no. 4 se lee: "Los miembros de la Organización, en sus relaciones internacionales, se abstendrán de recurrir a la amenaza o al uso de la 
fuerza contra la integridad territorial o la independencia política de cualquier Estado, o en cualquier otra forma incompatible con los propósitos de las Naciones Unidas". Dentro de ese cuerpo normativo, también se definen y regulan las coyunturas que plantea la guerra, así como la convivencia pacífica, la solidaridad internacional (referida a formas cooperativas y opciones de solución de los conflictos y enfrentamientos internacionales), incluyendo como excepciones a la prohibición de la guerra, las derivadas de autorización del Consejo de Seguridad de las Naciones Unidas, la legítima defensa contra la agresión y las luchas armadas para obtener la liberación, tópicos regulados dentro del Capítulo VII, arts. 39 ss. Para el internacionalista Charles Rousseau, se requieren cuatro condiciones para tener a la guerra como justa: "a) justo título, b) justa causa, c) necesidad y d) justa dirección de la guerra"3.

En cambio, el surgimiento de los conflictos internos, al considerársele tema más propio de cada Estado y de organizaciones políticas particulares, no ha sido materia de una consagración internacional, porque atentaría en gran medida contra el principio de libre autorregulación de los pueblos. Por eso, su ocurrencia se deja librada en materia de penalización al legislador local. En nuestro país, Ios alzamientos en armas se categorizaron como delitos contra el Régimen Constitucional y Legal, encarnados en las conductas de rebelión (art. 467) y sedición (art. 468), cuyas penas se han amoldado al ritmo de ascenso y agravamiento del conflicto interno.

En cuanto a la dinámica de la guerra, que parte de la aceptación de su realidad, la condensación de los principios de regulación del uso de la fuerza y de la discriminación de objetivos constituyen la razón de ser de la normatividad que se ha diseñado dentro del entorno internacional, conocido como ius in bellum. Al principio y atendiendo a la aparente imposibilidad natural de que una confrontación armada, que implica la utilización de todos los instrumentos con que cuente un Estado o un grupo, tanto violentos como engañosos, para conseguir el avasallamiento del adversario, tenga las regulaciones que obran como medición que pretende racionalización de lo irracional, lo cual ha hecho glosar la corrección del planteamiento a muchos de los estudiosos del asunto ${ }^{4}$.

Lo cierto es que la barbarie, la deslealtad y la felonía tienen también sus límites y siguen siendo tales, pese a su control y reducción. Como hay muchas formas de homicidios, despojos, secuestros y dosis diferenciables de afloramiento de la tendencia destructiva en el hombre, cuya medición se refleja en las magnitudes de su pesaje social, también se ha considerado que la guerra, pese a contrariar toda forma de supeditación a la juridicidad, debe, en su desenvolvimiento, abstenerse de trasponer los umbrales de lo necesario y adecuado de acuerdo con pautas éticas.

Con acierto se ha parangonado el adelantamiento de una guerra con el de un encuentro deportivo, como una pelea de boxeo, en donde de antemano se ha prestado la anuencia para que los púgiles se golpeen y zarandeen recíprocamente mediante la utilización sólo de sus puños enguantados y en determinadas partes de sus anatomías, sobre un cuadrilátero cuyas dimensiones son precisas, durante cierto número de asaltos de duración definida y en presencia de un árbitro. Desde luego, sólo se ha podido llegar a esa instancia cuando se ha comprobado que los contendientes reúnen condiciones mínimas de igualdad, como similar peso, lo que es imposible de exigir entre naciones en donde las poderosas aplastan a las débiles y luego se arrogan la condición de jueces.

Ver ROUSSEAU, Charles. Derecho Internacional Público. $3^{\text {a }}$ Ed. Barcelona: Ariel, 1966. p. 544.

4 Ver UPRIMMY YEPES, Rodrigo. «Sentido y Aplicabilidad del D. I. H. en Colombia» En: AA.V V. D. I. H. en Colombia. Bogotá: T. M. Editores, 1998. p. 80. 
Sin embargo, a partir del enriquecimiento de los arsenales estatales con artefactos nucleares, y la puesta en boga de las guerras frías, se colocó de moda el viejo aforismo de que "la amenaza es más fuerte que la ejecución". Lo cual, no ha impedido que las llamadas potencias emprendan campañas guerreras convencionales para impedir que entren en somnolencia las virtudes combativas de los integrantes de sus ejércitos y el sabor de la gloria, a veces tan esquivo, se vuelva a deslizar por sus gaznates, aunque pueda trocarse en hiel como en Vietnam o Irak. Pero en punto a reafirmar la postura de hombres a quienes la civilización los ha tocado muy adentro, en las bien remuneradas veladas y condumios que suceden como algo connatural a la suspensión o finalización de las hostilidades, el cuadro ya infalible, de los representantes de poderosas naciones, que en un gesto de benevolencia acceden a departir alrededor de las mismas apetitosas viandas con sus sparrings, para transmitir aires paternalistas al mundo y a sus apáticos electores. Se propone que para refrendación de su espíritu caballeresco, se adopten reglas que morigeren los horrores presenciados en el último enfrentamiento, con el propósito de aplicarse en los que tildan de improbables venideros $y$ se habla de la ética, del juego limpio, de superación de los excesos, de que la "fiesta" ${ }^{5}$ se celebre sin ampulosidades.

Sobre ese particular, ha sido copiosa la tinta que se ha derramado, desde posiciones como la de
Marcuse $^{6}$, que aludiendo a los movimientos revolucionarios internos, se esfuerza por descubrir la naturaleza del piso que pudiera soportarlos, instando a extraer los componentes históricos que permitan el alcance de una ganancia en el plano ético, entendido como búsqueda de mayor libertad y dicha. Resulta forzosa la remisión a Aristóteles ${ }^{7}$, pionero de la sistematización dentro de las facultades del alma, en virtud y felicidad y su relación con los sentimientos. Max Scheler $^{8}$ sitúa al amor como problema central de la ética y orientador de otros valores en los cuales se asienta ésta. Bilbeny ${ }^{9}$ conecta la escala de los valores con la razonabilidad, la naturaleza de lo obligatorio moral y su aproximación con lo bueno. Baurmann ${ }^{10}$ correlaciona las exigencias morales con los imperativos económicos, intentando demostrar su necesaria coexistencia. Cortina ${ }^{11}$, en medio del planteamiento de la paradoja entre imposibilidad y necesariedad, toma partido por la urgencia de hacer justicia para abonar el terreno a la vuelta de los valores tradicionales. Pasando por pensadores de todas las tallas, hasta Sontag ${ }^{12}$, que alerta sobre la influencia de los medios masivos de comunicación en la insensibilización de la conciencia colectiva, lo cual revierte en la conversión de lo horrendo en cotidiano y cursante.

Todos los trabajos verificados para fundamentar la escogencia de cortapisas que devuelvan las dosis de moderación, piedad y sensatez a esta expresión de salvajismo humano aluden sin ex-

\footnotetext{
5 Son frecuentes las comparaciones de la guerra con una fiesta, en cuanto ambas implican reunión material de los miembros del grupo alrededor de una causa común, desembolso o derroche ritual, inobservancia de prohibiciones y tabúes, exaltación colectiva, provocación de insensibilidad física y acompañamiento de sacrificios ceremoniales. Ver, entre otros, a BOUTHOUL, Gastón. La Guerra. Barcelona: Oikos-Tau. Johanna Givanel, 1971. pp. 65 ss.

6 Cf. MARCUSE, Hebert. Ética de la Revolución. 2a. Ed. Madrid: Taurus, Aurelio Álvarez R. 1970. pp. 141 ss. complementado en “La Sociedad Carnívora" Buenos Aires: Galerna. Miguel Grinberg, 1989, en especial en "Perspectivas de la Nueva Izquierda Radical". Cf. ARISTÓTELES. Gran Ética. Buenos Aires: Aguilar. Fco. de Paula Samaranch, 1961.

8 Cf. SUANCES MARCOS, Manuel A. Max Scheler: principios de una ética personalista. Barcelona: Herder. 1976.

$9 \quad$ Cf. BILBENY, Norbert. Aproximación a la Ética. Bogotá: Ariel, 1992.

10 Cf. BAURMANN, Michael. El mercado de la virtud. Barcelona: Gedisa. Ernesto Garzón Valdés, 1998.

11 Cf. CORTINA, Adela. Hasta un pueblo de demonios. Madrid: Taurus, 1998.

12 Cf. SONTAG, Susan. Ante el dolor de los demás. Bogotá: Alfaguara. Aurelio Major, 2003.
} 
cepción a la ética que, antes de ser un valor en sí misma, es la matriz de donde se desprenden los verdaderos fundamentos de la vida en sociedad, que posibilitan el respeto a los bienes jurídicos considerados dignos de extrema protección.

Nos parece, empero, que a medida que pasa el tiempo y se multiplican las disputas armadas colectivas, se recrudecen los ensañamientos, se refina la sevicia y se muestra más desnudo de solidaridad el hombre, que parece solazarse retornando a su primitivismo. En contadas ocasiones, a lo largo de los siglos, preceptos morales se cristalizaron en normas jurídicas. Otras veces flotaron densos y silenciosos dentro de la conciencia colectiva. Se abriga la engañosa tendencia a creer que modernidad y posmodernidad, por la apertura a la sintonización de todos los seres humanos en la misma onda globalizante, han fortalecido los valores yacentes en los espíritus.

No obstante, los hechos registrados le dan un sonoro mentís a tal especulación, puesto que la presencia de reglas como las mencionadas, sólo han servido para comprender la magnitud de las burlas y violaciones contra ellas suscitadas. El breve recorrido que hemos emprendido acaso nos sirva para detectar las contradicciones entre lo que se preceptúa y lo que se vierte en la práctica en tópicos como el honor, métodos de tomar vidas ajenas, rendición y trato de prisioneros y heridos, conducta en el área de operaciones, que se contraponen a la idea de guerra total.

Ya hemos develado que la obtención de la victoria configura un sentimiento que supedita reservas y sujeciones a la búsqueda de lo bueno y lo justo. Que desde las primeras confrontaciones se han impuesto prácticas y estados de ánimo vergonzantes. La traición, los pozos envenenados y los instrumentos vulnerantes envenena- dos en las guerras griegas, entre los años 500 y 400 a.C. se registran con habitualidad, así como luego en la Edad Media, la dejación de cadáveres de animales muertos en lugares propicios para que su descomposición favoreciera la transmisión de bacterias y virus, que permiten sorprender los primeros pasos de la guerra bacteriológica. Esta forma particular de hacer la guerra fue declarada ilegal en conferencia celebrada en Washington en 1925, lo que para algunos autores fue un error, ya que en muchos eventos la utilización de otros medios destructivos no vedados ocasiona pérdida de vidas y daños materiales que se habrían podido evitar mediante el empleo de "gases" que producen inutilización transitoria, sin secuelas posteriores ${ }^{13}$.

Atrás puntualizamos que la influencia del cristianismo fue definitiva para imponer en especial en Europa durante la Edad Media y con posterioridad a ella un complicado código en el que traición, sevicia, insidia, alevosía, eran consideradas como el ingrediente que desbordaba el vaso de lo soportable, a la par que se privilegiaba el heroísmo en el combate y la lealtad al amo feudal. Se construyó, además, el estereotipo del "caballero" que orondo se desplazaba por los campos de batalla, invitando a ser emulado por su fidelidad y magnanimidad con el enemigo caído en cabal reyerta.

Sabemos que la cortesía se difuminó de forma considerable en Europa y que el intercambio de misivas entre generales antagonistas se hizo frecuente. En Japón, fue proverbial el trato que siguió a los períodos de venganzas familiares y colisiones tribales, plasmándose en el llamado manual del "caballero y el arco", cuyo fundamento era la lealtad de un militante del ejército frente a su superior que, gracias a la cultura confuciana, se adaptó a un clima de búsqueda de la paz, que luego

13 Cf. MONTGOMERY, Mariscal. Historia del arte de la guerra. Madrid: Aguilar. 1969. pp. 547-548. "Incapacitar temporalmente a un gran número de enemigos es ciertamente mejor que emplear armas mortiferas en masa y destruir la propiedad inanimada de los no combatientes". 
evolucionó en el culto denominado "bushido", que significa "el camino del guerrero", catalogado como un sistema ético de fidelidad en época de guerra, influido por la idea de moderación y tolerancia, que en la hecatombe bélica de 1939 a 1945 demostró su fragilidad, pues los uniformados japoneses rubricaron el predominio de la brutalidad en el trato dispensado a sus prisioneros, a quienes sometieron a las más denigrantes prácticas.

La Ilustración predicó políticas de compasión y obtuvo la anuencia de muchos monarcas. En Francia, Luis XIV y Luis XV rehusaron emplear "líquidos infernales" que les ofrecieron los químicos y en 1855, cuando Lord Dundonald propuso en secreto el empleo de nubes de humo asfixiantes en el sitio de Sebastopol, su sugerencia fue desestimada por los altos mandos británicos. Napoleón III, diez años más tarde, frenó los experimentos que florecían contando con perros como conejillos de indias, a los que se les aplicaban granadas asfixiantes, al expresar que tan desalmados procedimientos jamás serían implementados por el Ejército Francés porque iban contra la "ley de las naciones".

Se consolidó en el decurso del siglo XVII la usanza de permitir a los defensores de una fortaleza capitular con "honores de guerra", que consistía en la ritualidad de abandonar su refugio con el acompañamiento de las armas y despliegue de banderas al ritmo de los sones interpretados por una banda de músicos, para luego proceder a la rendición.
En 1862, Henri Dunant, un filántropo suizo, publicó un libro en el que dibujó más que describió los padecimientos de los heridos tendidos en el campo después de la batalla de Solferino, lo cual impactó con fortaleza inusual a la opinión pública europea ${ }^{14}$. Apremió a la constitución de sociedades de ayuda voluntarias $y$, como secuela de ello, 16 países europeos se hicieron representar en una conferencia reunida en Ginebra al año siguiente, en donde se sentaron importantes bases acerca del auxilio que se debía prestar a los heridos y del permiso de hacerlo por las partes trabadas en el conflicto sin importar su procedencia. Pues la tradición que predominaba era la de la concertación por los bandos enfrentados de una suspensión de hostilidades luego de cesar la lucha, para facilitar la inhumación de los muertos y el retiro de los lesionados. Pero cuando no se daba esa tregua, los convenios eran letra inane, ya que nadie se interesaba por atender a los heridos enemigos, alegando la existencia de prioridades más urgentes.

En 1864 se suscribió la primera Convención de Ginebra, que fue objeto de sucesivas revisiones. Se constituyó un Comité de la Cruz Roja Internacional para aliviar la situación de los soldados heridos en el campo de batalla, y más tarde se responsabilizó de la supervisión de los campos de prisioneros de guerra. Se instituyó que los combatientes incapacitados han de ser tratados con respeto y atendidos de manera adecuada, cualquiera sea su nacionalidad. Los vehículos que los transporten, sean terrestres, marítimos o aé-

\footnotetext{
14 VER DUNANT, Henri. Recuerdo de Solferino. Ginebra, Comité Internacional de la Cruz Roja. Sergio Moratiel Villa, 1982, en donde después de relatar sucesos sin duda conmovedores, se formula la pregunta: iNo se podrán fundar sociedades voluntarias de socorro cuya finalidad sea prestar o hacer que se preste, en tiempo de guerra, asistencia a los heridos? Pues hay que renunciar a los deseos y a las esperanzas de los miembros de la Sociedad de Amigos de la Paz o a los sueños del abate de Saint Pierre y a las inspiraciones del conde de Sellon pues continúan matándose los hombres los unos a los otros sin odiarse; pues el colmo de la gloria es, en la guerra, exterminar al mayor número posible de adversarios; pues se asegura, como afirma el conde Joseph de Maistre, que la "guerra es divina"; pues se excogitan todos los días, con una perseverancia digna de mejores fines, medios de destrucción más terribles que los ya poseídos; pues se estimula a los inventores de estos mortíferos artilugios en la mayoría de los grandes Estados de Europa, que se arman a cual mejor". (p. 117).
} 
reos, los centros de salud que los acojan, el personal de médicos, paramédicos, capellanes y administradores que los reciban, gozarán de un estatus de protección dondequiera que actúen, así sea en medio del fragor de los combates y se distinguirán por los signos visibles de una bandera y un brazalete con el logotipo de la Cruz Roja, que con el tiempo han sido ultrajados y utilizados por varias fuerzas para engañar a la contraria.

La suerte de los prisioneros de guerra ha sido infernal en varios estadios de la historia, pues al principio era usual matarlos en medio de dolorosas torturas o esclavizarlos. Luego se pretextó para justificar tanta crueldad que no se contaba con raciones extras para alimentarlos. Que su traslado a lugares casi siempre distantes constituía un auténtico lastre y que las naves de guerra eran muy pequeñas para albergar pasajeros adicionales. La historia, sin embargo, nos da cuenta de detalles de nobleza conmovedores. En 1587, un año antes de la derrota de la Armada Invencible, el comandante en jefe de la Marina Española había recibido órdenes de matar a todo hombre que fuera sorprendido a bordo de un navío inglés. Pero la victoriosa reina Isabel I envió a España a todos los marinos de esa nacionalidad que naufragaron en las costas de Irlanda y fueron muy afortunados al caer en manos de sus soldados en lugar de ser eliminados por los irlandeses.

En 1899, se celebró la primera conferencia de La Haya, en donde se aprobaron resoluciones que tendían a evitar la iniciación de las hostilidades, rodeando este paso de exigencias muy estrictas (que pronto se vieron afectadas por la obsolescencia), al cuidado de heridos, enfermos, náufragos y prisioneros de guerra y a imponer reglas elementales merecedoras de respeto en la conducción de la guerra y a la selección de los medios que permitirán adelantarla. Allí, se clarifican de manera sorprendente pautas éticas que han prevalecido, que siguen inspirando el mundo del derecho y que, entraron a construir el cuerpo del acervo consuetudinario, mencionado como patrimonio común de la humanidad. Por ejemplo, allí se prohibió el uso del veneno y armas ponzoñosas, pero no se condenó la guerra con gases ni la producción de nubes tóxicas, aunque se vedó "el uso de proyectiles cuyo único objeto sea la difusión de gases asfixiantes"; esto significaba con certeza el bombardeo con granadas de gas, pero en general dejó la cuestión un tanto borrosa. La Conferencia, empero, descalificó el uso de balas explosivas de forma taxativa.

En 1907, los frutos de las conversaciones comunes entre los Estados europeos fueron mucho más exitosos, pues se plasmaron en la codificación los mejores principios que se han diseñado; la prueba está en su trascendencia, en cuanto hace relación con temas como los prisioneros de guerra. Se estatuyó que todas las pertenencias personales de un cautivo, excepto sus armas, se conservarían en su poder, haciendo parte de su propiedad. En lo concerniente a alimentos, alojamiento y vestuario, a los privados de su libertad se les debería dar el mismo trato que a los integrantes del ejército captor. En fecha posterior se acordó que ningún prisionero sería obligado a declarar a sus guardianes ninguna información que no fuese su número, rango y nombre. En el siglo XX, los Estados comunistas fueron acusados de una innovación al sistema del trato a los prisioneros conocido como "lavado de cerebro", que convertía a éstos en difusores favorables de la ideología de sus captores.

Se proscribió el saqueo, que había servido como estímulo a quienes formaban parte de los ejércitos. Así mismo, se declaró que no se podría matar o herir a un enemigo que se hubiere rendido y atacar o bombardear ciudades, poblaciones y aldeas que no estuviesen defendidas (se puso en boga la expresión "ciudad abierta"). También se proclamó en la Conferencia de 1907 que no habría lugar a romper fuegos "sin previa y explícita advertencia en forma de una declaración de 
guerra condicional". Esta consideración se justificaba, ya que, según sabemos, en 1904 Japón emprendió su lucha con Rusia sin previo ultimátum o declaración, al igual que había procedido contra China en 1895 y habría de hacerlo de nuevo contra Estados Unidos en diciembre de 1941 en Pearl Harbor. La Segunda Guerra Mundial, de idéntica forma, produjo incidentes fronterizos deliberados, destinados a proporcionar un pretexto en apariencia válido para declarar la guerra, cuando el chivo expiatorio, de manera terca, se obstinaba en facilitar alguno.

En 1922, se concertaron en la Conferencia de Washington algunas disposiciones que enriquecieron el repertorio jurídico del "derecho de guerra" sobre la limitación de armamentos. En particular, se prohibieron los bombardeos aéreos con el propósito de generar zozobra en la población civil, destruir o dañar propiedad privada de carácter no militar, o afectar a no combatientes. De la misma forma, se impidió el empleo de gases asfixiantes y venenosos (que no se utilizaron en la Segunda Guerra Mundial). Se declaró ilegal la guerra bacteriológica. Pero al margen de tan loables pretensiones, tanto en la Guerra Civil Española, que comenzó en 1936, como en la Segunda Mundial se registraron muchos eventos de bombardeos con finalidades terroristas $y$ de personas civiles sacrificadas. Incluso las incursiones aéreas mejor planificadas estaban expuestas a dañar la propiedad privada. Se patentizaron las debilidades del Convenio de 1929, que pretendió cubrir las falencias de los anteriores, que se estructuraban alrededor de la obligatoriedad predicada sólo para las Partes que lo suscribieron, quedándose por fuera de su égida más de las dos terceras partes de los damnificados, en especial rusos y japoneses.

Además, surgió una nueva categoría de personas no tenida en cuenta por los anteriores pactos: Ios miembros de la resistencia en los países ocupados por las Fuerzas del Eje, que fueron declarados guerrilleros. Aún se recuerdan los rostros demacrados de civiles, mujeres y niños, las escenas de los campos de concentración nazis, la tierra arrasada, el imborrable hongo nuclear de Hiroshima y Nagasaki como símbolos de una pesadilla que se ha prolongado, todo lo cual condujo a la realización del encuentro diplomático de los principales representantes de las naciones del orbe en 1949, en la que se adoptaron Ios cuatro Convenios de Ginebra, referidos en su orden a: $1^{\circ}$. Tratamiento de la situación afrontada por los heridos, náufragos y enfermos de las fuerzas armadas en campaña. $2^{\circ}$. Alivio de la suerte de heridos, enfermos y náufragos de las fuerzas armadas en el mar. $3^{\circ}$. Trato debido a los prisioneros de guerra y $4^{\circ}$. Protección de personas civiles en tiempo de guerra. Se invocó como basamento de su expedición la necesidad de preservar la dignidad y respeto humanos, que servirían de base luego en nuestra Constitución de 1991 y que por lo mismo soportan nuestro Estado social de derecho e inspiran el señalamiento de todos Ios bienes jurídicos protegidos. Sus finalidades: la salvaguardia y socorro de quienes no intervienen en el enfrentamiento o han perdido su capacidad para seguir participando en él, como heridos, enfermos, náufragos o prisioneros. Como cobertura de su aplicación se señaló el de conflicto armado internacional, a excepción del art. $3^{\circ}$, común a los cuatro instrumentos, que se dirige a abarcar los conflictos internos para amplificar la protección a los mismos destinatarios incluidos en los cuatro Convenios. En 1954, en La Haya, se suscribió un convenio inherente a la protección de bienes culturales, que se incluyeron en la normatividad de Ginebra por ser bienes no militares.

La proliferación y agudización de conflictos en todo el mundo, pero ante todo las violaciones a los existentes y el brusco giro que las nuevas modalidades violentas, en donde las diferencias entre lo nacional e internacional no satisfacían las expectativas creadas con holgura, tornaron imprescindible la celebración de un nuevo en- 
cuentro en Ginebra, entre 1974 y 1977, cuyo coIofón consistió en la aprobación de dos protocolos adicionales. El primero se ocupó de completar y desarrollar las disposiciones de los Convenios de Ginebra, diseñados para los conflictos internacionales, ampliando su radio de aplicación a las llamadas guerras de liberación nacional, ocupación extranjera y regímenes racistas; el segundo, de completar y desarrollar el art. 3º. Común, quedando restringido su ámbito de aplicación material a los conflictos armados internos que hubiesen alcanzado un determinado grado de intensidad.

Amerita que tengamos presente, por lo menos, el Convenio de Naciones Unidas de 1980 sobre la proscripción y limitación de ciertas armas que, pese a hallarse agrupadas como convencionales, son reputadas por su potencial destructivo y alcances indiscriminados como particularmente nocivas. Dentro de ellas se incluyen las minas antipersonales y "armas trampa". Por igual, es digna de mención la creación de la Corte Penal Internacional, mediante el Estatuto de Roma, aprobado en Colombia mediante la Ley 742 de 2002.

Dentro de nuestro Código Criminal, podemos ensayar la clasificación de los tipos que allí figuran ubicados en conexión con los bienes jurídicos que se afectan o corren peligro, así:

\section{- De manera directa:}

- Vida: homicidio y omisión de medidas de socorro y asistencia humanitaria.

- Integridad personal: lesione y omisión de medidas de socorro y de asistencia humanitaria.

- Libertad (autonomía personal): tortura, actos de terrorismo, toma de rehenes, detención ilegal y privación del debido proceso, constreñimiento a apoyo bélico, destrucción o utilización ilícita de bienes culturales o de lugares de culto, represalias, deportación, expulsión, traslado o desplazamiento forzado de población, reclutamiento ilícito.

- Libertad sexual: acceso carnal violento, actos sexuales violentos, prostitución forzada o esclavitud sexual.

- Dignidad personal: tratos inhumanos y degradantes y experimentos biológicos.

- Recta impartición de justicia: detención ilegal y privación del debido proceso.

- Patrimonio: despojo en el campo de batalla, destrucción y apropiación de bienes, destrucción o utilización ilícita de bienes culturales o de lugares de culto, represalias, exacción o contribuciones arbitrarias.

- Salud pública: destrucción de bienes o instalaciones de carácter sanitario.

- Seguridad pública: ataque contra obras e instalaciones que contienen fuerzas peligrosas, atentados a la subsistencia y devastación.

- Recursos naturales y medio ambiente: destrucción del medio ambiente.

\section{- De manera indirecta:}

- Vida: utilización de medios y métodos de guerra ilícitos, perfidia, actos de terrorismo, actos de barbarie, tratos inhumanos y degradantes y experimentos biológicos, toma de rehenes, obstaculización de tareas sanitarias y humanitarias, atentados a la subsistencia y devastación, omisión de medidas de protección a la población, destrucción del medio ambiente.

- Integridad personal: utilización de medios y métodos de guerra ilícitos, perfidia, actos de terrorismo, actos de barbarie, tratos inhumanos y degradantes y experimentos bio- 
lógicos, toma de rehenes, obstaculización de tareas sanitarias y humanitarias, atentados a la subsistencia y devastación, omisión de medidas de protección a la población, destrucción del medio ambiente.

- Patrimonio: utilización de medios y métodos de guerra ilícitos, actos de terrorismo, destrucción de bienes o instalaciones de carácter sanitario, ataque contra obras e instalaciones que contienen fuerzas peligrosas, atentados a la subsistencia y devastación, destrucción del medio ambiente.

- Seguridad pública: utilización de medios y métodos de guerra ilícitos, actos de terrorismo, destrucción y apropiación de bienes.

- Recursos naturales y medio ambiente: utilización de medios y métodos de guerra ilícitos, actos de terrorismo, destrucción y apropiación de bienes.

- Salud pública: utilización de medios y métodos de guerra ilícitos, actos de terrorismo, obstaculización de tareas sanitarias y humanitarias, destrucción y apropiación de bienes.

- Libertad: tratos inhumanos y degradantes y experimentos biológicos.

Como lo hemos observado hasta ahora, el enlace que se produce entre los tipos agrupados en el acápite con precisos bienes jurídicos diseminados a lo largo de nuestro Estatuto Criminal es tan íntimo que desvirtúa el predicamento de que pueda esa combinación, que no se diseñó con tal finalidad, derivar en la fabricación de otro nuevo, construido al amparo de un valor específico. Más bien la homogenización que se ha obtenido se explica por la superposición de elementos que puntualizaremos en seguida.
Empero es patente que en medio del afán que asistió al legislador colombiano por nutrir su arsenal normativo de los mejores instrumentos, de cara a la agudización del conflicto nacional y con el pretexto de buscar la concordancia de los cuerpos legales con la Nueva Constitución, poco se preocupó por incorporar a su quehacer la mentalidad del buen orfebre y, en cambio, como albañil tosco y barato, tomó los bloques enteros de convenios, tratados, protocolos y resoluciones internacionales $y$, a punta de escoplo, les abrió campo en las entrañas de la anatomía de nuestra normatividad penal, sin percatarse de sus medidas ni del lugar que dentro del conjunto les correspondía.

Desde luego, en el Congreso el Proyecto fue sometido a retoques auspiciados por los grupos de presión de siempre, que terminaron por deformar de tal manera el grotesco edificio que lo tornaron ininteligible, como lo descubriremos luego. Pese a esos dislates, es aún posible rescatar algunos conductos enclavados en la Parte general, que nos pueden ilusionar con la existencia de un sistema, que aproxima nuestra sustantividad legal a la internacional. De esta clase son: el art. $2^{\circ}$ que integra la temática de todos los compromisos adquiridos por Colombia con otras naciones al Código, como lo prevé la Carta Política, y amplía su radio de acción; el art. $8^{\circ}$ que recoge la importante excepción a la prohibición de no ser juzgado dos veces por los mismos hechos, que proviene del Derecho Internacional; el art. 15, que alude a la territorialidad por extensión, cuya aplicabilidad está supeditada a las salvedades contenidas en el Derecho de Gentes; el art. 16 que, dentro de las posibilidades de vigencia de los estatutos real, personal y universal, determina las excepciones al juzgamiento foráneo y da luz verde al conocimiento de los delitos de colombianos al servicio del Estado y de extranjeros cuya extradición no hubiere 
sido concedida o aceptada; el art. 17, sobre validez de sentencias extranjeras; el art. 18, procedencia de la extradición; el art. 32, n. 4, con respecto a la inoperancia de la orden de superior como causal excluyente de responsabilidad frente a genocidio, desaparición forzada y tortura.

Debe destacarse que nuestro hacedor de leyes no se contentó con traer al ámbito colombiano las conductas señaladas en el art. $3^{\circ}$ Común a todos los Convenios de Ginebra, ni con los del Protocolo Adicional II de 1977, como la perfidia. Se absorbieron, además, otras propias del Consejo de Seguridad de las Naciones Unidas, que aludieron a crímenes de guerra, como el acceso carnal violento.

\section{ELEMENTOS GENERALES DE LOS TIPOS}

\subsection{Sujeto activo}

Pese a que por arte de birlibirloque, en la que nuestro legislador es un verdadero experto, aprovechándose la objeción infundada del ejecutivo al texto aprobado por el Congreso, desapareció la calificación de combatiente, con la que en su origen se catalogaba al autor de la inmensa mayoría de conductas explicitadas bajo el Título respectivo, esta señal particular ha resistido la aplicación de los más poderosos detergentes que pululan en el mercado y, como la famosa de Caín, más que verse, se huele y se siente cual sombra tozuda en el alma de los torturados cuerpos. Y no podía ser de otra forma, ya que hace parte de la esencia de las conductas, puesto que, como lo afirmaría Perogrullo, iquién, que no la posea, se pasearía orondo por los campos de batalla, sembrando el terror entre la población civil, con su afilada guadaña? Es más, sería ingenuo y hasta ilógico que un tercero apareciera como ángel exterminador de inocentes, en medio de un enfrentamiento armado y aprovechara la distracción de quienes se están jugando la vida en el lance para atacar a mansos corderos y acercarlos a mejor vida, lo que no suena cercano a las experiencias que la humanidad ha acuñado hasta el presente.

Así pues, la ausencia de calificación del sujeto de tales conductas permitiría a su autor usufructuar dicha situación, que lo enviaría de inmediato a la jurisdicción de las normas ordinarias del Código Penal, pero que en ningún caso se compadece con el sentido que se ha querido imprimir a estas interdicciones. Tengamos en cuenta que el fundamento de la expedición de las normas aquí apresadas emana de la voluntad de moderar el uso de la violencia aneja a la guerra, sea entre países, interna o con connotaciones internacionales, de asignarle límites, de meterla en cintura, para quienes la generan, dándole una envergadura que depende de sus intervenciones.

Por eso, al Derecho Internacional no le interesa el ejercicio de una fuerza de restringidos alcances ni la producida por quienes no son los protagonistas de la relación dialéctica que, trabándose, da a luz el clima bélico, que puede conservarse gracias al mantenimiento de pujas mutuas dirigidas a la abolición de toda resistencia. Incluso, no se sopesa el grado ni la intensidad del aporte individual, sino en cuanto éste ha enriquecido el espectro de la gran erupción de la onda energética que la comunidad internacional busca adecuar a proporciones ideales, conforme a un sentido ético y racional.

Se precisa estar dentro del huracán, desde donde se aprovecha su impulso, que de suyo es destructivo, pero que no puede desbordarse so pena de someterse a reproches por sus excesos. Sería absurdo intentar sancionar a los creadores de un fenómeno como responsables de una extralimitación que no han causado. Así mismo, incriminar a quienes ocasionaron los actos de exceso, sin que éstos dependan del fenómeno, cuando se exige que haya conexidad entre ambos. Por eso, el actor de los comportamien- 
tos que suponen la superación de los mojones aludidos sólo puede ostentar la calidad de legitimado para permanecer dentro del ámbito de su contención. Una ninfa no puede abandonar su capullo si antes no lo habitaba.

Sin embargo, existe otro argumento de similar consistencia: merced al principio de integración del art. $2^{\circ}$ del C. P., reflejo del art. 93 de la C. N., todas "las normas y postulados que sobre derechos humanos se encuentren consignados en ...los tratados y convenios internacionales ratificados por Colombia harán parte integral de este Código". Lo que en buen romance quiere decir que si los instrumentos de ese carácter, en los que figura como Parte nuestro país, creados para proteger los D.H., como resulta sencillo verificarlo en este caso, tienen como sustento la circunstancia de la guerra o conflicto interior de la magnitud requerida y para cercar de mejor forma las descripciones abstractas y genéricas, emplea expresamente para consignar a su autor el vocablo combatiente ${ }^{15}$, el arquitecto de las normas no puede -dejando afluir bajo el disfraz de originalidad su capricho- no sólo variar, sino desnaturalizar al protagonista de la acción, puesto que propiciaría un choque entre las dos posiciones, del cual, por hermenéutica constitucional y sentido común, siempre saldría gananciosa la constitucional que le otorga a los acuerdos, tratados y pactos internacionales -como que se haIlan pareados con las normas supremas- una estatura prevalente en la jerarquía normativa sobre los preceptos de un Código.
De otra parte, resultaría descabellado suponer siquiera que para atender los compromisos internacionales adquiridos por el país, se estuviera capitalizando la ocasión para hacer con exactitud lo contrario. Incluso, si nos atenemos a la decisión tomada por la Honorable Corte Constitucional frente a situaciones como las previstas en el Título, no se requeriría siquiera de la ratificación de los documentos contractuales ${ }^{16}$.

El prototipo clásico del combatiente es, en los viejos lienzos caballerescos, el gallardo jinete que protegido por reluciente armadura, y blandiendo simétrica pica, que mantiene firme, se lanza montado en su corcel de lujo contra un contrincante de similares características a las suyas, para jugarse la vida por un ideal plausible, bajo el atento escrutinio de sus iguales, los nobles y el pueblo, que ratifica una vez más su ingenuidad al integrar la idea de justicia a esos lances. Algunos dirán, no sin razón, que como paradigma de la guerra no funciona por la poca trascendencia que en el plano general cobra esa aplicación de la fuerza, lo que nos obliga a clonar los caballeros andantes a cada lado, hasta formar dos ejércitos, que si queremos ser consecuentes con pretéritas usanzas, se colocarán bajo el patronato de reglas casi siempre de origen consuetudinario. Del surgimiento de las facultades de agresión, inteligencia, astucia, haremos depender la formulación de una tabla que, conforme a nuestra percepción de lo correcto o incorrecto, aprobaremos o rechazaremos, en términos de bue-

\footnotetext{
15 Su uso es reiterado en la jerga internacional. Por ej. Alfred Verdross (Derecho internacional Público, Madrid: Aguilar, 1976, p. 423), menciona: "El derecho de la guerra autoriza solo a determinados grupos de personas a llevar a cabo acciones bélicas. Pero, además, estos actos sólo pueden dirigirse contra grupos de personas también determinados. Estos sujetos y objetos de actos bélicos quedan comprendidos bajo la denominación de beligerantes o combatientes legítimos".

16 En la Sentencia C-574 de 1992, la Corte Constitucional expresó: Los principios del derecho internacional humanitario plasmados en los Convenios de Ginebra y sus Protocolos, por el hecho de constituir un catálogo ético mínimo aplicable a situaciones de conflicto nacional e internacional, ampliamente aceptados por la comunidad internacional, hacen parte del ius cogens o derecho consuetudinario de los pueblos. En consecuencia, su fuerza vinculante proviene de la universal aceptación y reconocimiento que la comunidad internacional de Estados en su conjunto le ha dado al adherir a esa axiología y al considerar que no admite norma o práctica en contrario. No de su eventual codificación como norma del derecho internacional... De ahí que su respeto sea independiente de la ratificación o adhesión que hayan prestado o dejado de prestar los Estados a los instrumentos internacionales que recogen dichos principios. El Derecho Internacional Humanitario es, ante todo, un catálogo axiológico cuya validez absoluta y universal no depende de su consagración en el ordenamiento positivo".
} 
na o mala, de cara al trascurso de la medición de fuerzas, lo cual hacemos extensivo al resultado.

No obstante, en la práctica sería muy simplista hacer correlativos los términos de combatiente con quien empuña el instrumento vulnerante desde un observatorio demasiado inmediato. A medida que ha pasado el tiempo, las organizaciones humanas se han complejizado más, característica de la que no se escapa la guerra como un producto social con profundo nutrimento económico, que es y que nos impulsa a ir más allá del lato brazo armado de un conglomerado. Sabemos que la exhibición de armas, su empleo y sus resultados, no puede apreciarse apenas con respecto a su operador directo, porque intuimos que quien acciona un gatillo o un detonador es apenas un eslabón de la larga cadena de seres humanos que han prestado su concurso para que se dé tan lamentable acontecimiento y, por esa razón, nos resistimos a dejarlos por puertas a la hora del reparto de responsabilidades. Pero ello ocurre al aplicar nuestro sentido de justicia al fenómeno de la guerra, cuya presencia aislada no se eleva como fundamento del reproche para la mentalidad del juez supranacional. Lo que lo contornea es avanzar más allá del mismo por regiones vedadas a quien utiliza la violencia, no frente a quienes han dado el impulso primigenio para que ella se desenvuelva.

En otras palabras, nos parece aberrante que a Ios magnates que se nutren del conflicto, a los comerciantes de armas, a los causantes de las desigualdades sociales no se les lleve ante los tribunales como criminales de guerra. Pero esa actitud encuentra asidero en la mismidad al hecho bélico que exige para deducir responsabilidad no frente a la confrontación, sino a sus secuelas, magnificadas por la determinación consciente de romper la sujeción a los perímetros que se había fijado a su utilizador directo, que es el combatiente. Lo anterior sin perjuicio de que en cada evento concreto, y eso habría de profundizarse en lo internacional, alguien pudiera vincularse como interviniente en su condición de determinador o cómplice, porque seguimos pensando que quien no reúna la calidad de combatiente no podrá ser autor de estas infracciones, desde luego a excepción de las figuras contenidas en los arts. 148 y 157 del C.P., pues resulta palmario que se adquiere un deber de particulares ribetes, desprendido del rol de combatiente, que tiene una significación plena en lo atinente a la regulación del empleo de la fuerza, para no acrecentar por encima de lo "normal" el riesgo tolerado. Se le reconoce a cualquier persona sea que la capacidad para apersonarse del rol, por el solo hecho de actuar de forma beligerante en un conflicto armado, sea que pertenezca a los cuerpos operativos del organismo castrense institucionalizado o simplemente adscrito a él, o a tropas irregulares, que contiendan entre sí o con regulares, dependiendo de la clase de contienda que se establezca.

El Convenio de La Haya de 1907, en su art. $1^{\circ}$ fija importantes pautas en torno a la figura para especificar su calidad y condiciones, otorgándole la primera al ejército, a las milicias y a los cuerpos de voluntarios, exigiéndoles que: a). Tengan a la cabeza una persona responsable por sus subalternos, esto es, que se registre un principio organizacional. b). Ostenten una señal como distintivo fijo y reconocible a distancia. c). Se lleven las armas de manera franca. En este evento, el art. 44, Núm. $3^{\circ}$ del Protocolo I Adicional a los Cuatro Convenios de Ginebra amplió la condición al porte del armamento de manera abierta durante todo el tiempo de duración del enfrentamiento o en el lapso de visibilidad para el enemigo, previo a la iniciación del ataque. $Y$ d). Se sujeten en las operaciones a las leyes y costumbres de la guerra.

Además, habría que estudiar problemáticas tan delicadas como la de la utilización de dispositivos jurídicos connaturales a ciertos manejos grupales y al respeto a la autoridad, como la or- 
den. Desde luego que por tratarse de un crimen de guerra no desaparecen las posibilidades de responder por él a título de autor intelectual o mediato, determinador o cómplice.

El estatus de beligerancia ${ }^{17}$ es una categoría diversa no exenta de peligrosas aristas es la concerniente que, por innecesario para los fines del presente trabajo, nos abstendremos de tratar aquí.

\subsection{Sujetos pasivos}

Entendidos como los titulares de los bienes jurídicos tutelados, se concentra en esta categoría la verdadera esencia de los comportamientos reseñados en el Código, los cuales, como ya lo anotamos, corresponden a varias especificaciones que para fines didácticos señalaremos así:

\section{- Miembros población no combatiente}

Uno de los grandes criterios -si no el principalque adquiere relevancia mayúscula es el referido a la búsqueda de una cobertura legal efectiva para los bienes jurídicos de quienes se encuentran ajenos al conflicto, porque carecen de la calidad de combatientes en la medida en que se han marginado de los sucesos bélicos y se han mantenido sin empuñar las armas, lo cual los situaría en condiciones de exigir que, como no han creado el riesgo que perturbaría bienes ajenos, no tienen por qué resultar los propios en peligro, o afectados por las vicisitudes propias de los enfrentamientos ${ }^{18}$. También aparecen incluidos los individuos que quedan fuera de combate, y pierden su rol de tales, como acontece con heridos y enfermos de cierta con- sideración, rendidos, náufragos y prisioneros. Es decir, se agrupan dentro de las previsiones para otorgarles la condición de protegidos, que en estricto sentido significa, por exclusión, que no participan como unidades de combate, porque se han mantenido afuera del mismo en un plano activo o, si militaron dentro de alguno de los bandos enfrentados, se hallan incapacitados para la lucha. En dicho contexto, podemos mencionar dos clases de sujetos pasivos, que desde luego se ubican dentro de la común noción de protegidos:

- El individuo. Ya que se hace indispensable concretar en hipótesis determinadas el alcance de la cobertura establecida a titulares definidos, se infieren esferas de auxilio internacional al individuo como tal, en casos específicos como la vida, de manera directa (art. 135), de forma indirecta (arts. 144, 145, $152,160,161$ ), la integridad personal (arts. $136,137,144,145,152,160,161$ ), la libertad, (arts. 137, 138, 139, 141, 146, 147, 148, $149,150,159,162,163$ ) y al patrimonio (arts. $154,155,156,157,160)$.

- La sociedad. Su afectación parte de la caracterización suya como conglomerado de personas que, como tal, posee atributos de reconocimiento permanente, que no tienen por qué verse afectadas por la presencia de disensiones armadas de magnitud grave como las que despiertan el interés internacional. La misma esencia de los bienes jurídicos afectados o puestos en peligro remite su titularidad al colectivo social, con prescindencia de la legitimidad que pueda ale-

17 El profesor Alejandro Ramelli ha realizado un importante aporte a la discusión en: Derecho Internacional Humanitario y estado de beligerancia. Bogotá: Universidad Externado de Colombia, 1999.

18 El art. 3 Común determina cuál es el ámbito de protección, como se desprende del núm. I del mismo: "Las personas que no participen directamente en las hostilidades, incluidos los miembros de las fuerzas armadas que hayan depuesto las armas y las personas puestas fuera de combate, por enfermedad, herida, detención o por cualquier otra causa, serán, en todas circunstancias, tratadas con humanidad, sin distinción alguna de índole desfavorable basada en la raza, el color, la religión o la creencia, el sexo, el nacimiento o la fortuna o cualquier otro criterio análogo". 
gar cualquiera de los bandos enemigos. Estos valores son: salud pública (arts. 144, 153, 155), seguridad pública (arts.144,157, 160), recursos naturales y medio ambiente (arts. 164) y patrimonio cultural (art. 156).

\section{- Miembros población combatiente}

Dentro de este apartado, se otorga la titularidad de los bienes jurídicos a los combatientes que conserven esa capacidad, en prosecución de la idea, muy cara a la comunidad internacional, de imponer límites en el ejercicio de la violencia no sólo a las manifestaciones externas del conflicto, sino también al respeto de cierta ética entre quienes se enfrentan, cuya trasgresión afectaría al contendiente mismo. Por ello, la colocación de talanqueras obedece al presupuesto de obtener de los enzarzados en la lucha el compromiso de no sobrepasar frente al contrario condiciones de limpieza y lealtad. Los tipos que se han diseñado se distinguen -como es obvio- por no señalar de forma expresa a personas protegidas y tienden a la salvaguardia de combatientes en vida e integridad personal (arts. 142, 143, 145, 148,153, 155), libertad y privación del debido proceso (art. 149) y patrimonio (art. 155, 163).

\subsection{Modelos comportamentales}

Se ha enfatizado a lo largo de este trabajo que los varios verbos rectores empleados por el legislador, en cuyo estudio no nos detendremos, se hallan acompañados por la específica circunstancia de tener existencia, con ocasión o en desarrollo de un conflicto armado, con lo cual se provee la realización de un marco de precisión conceptual ineludible, cuya significación hemos tratado de establecer en este trabajo. Se aprecia que en materia de conflictos internacionales, no hay mayores inconvenientes en cuanto a su determinación, pero frente al reconocimiento de lo que debemos alinderar como internos, nos surgen vastas e intrincadas perplejidades en punto a su magnitud, alcances y naturaleza, para que pueda invocarse la normatividad internacional, puesto que no todo enfrentamiento que se suscite dentro de los espacios en donde cada país ejerce su soberanía, se eleva a los rangos necesarios para que sea reputado como digno de movilizar los mecanismos preceptivos consignados en los textos internacionales. El art. $3^{\circ}$ común a los cuatro Convenios de Ginebra, en comunicación con la temática desarrollada en el Protocolo II Adicional, menciona que debe contarse dentro de las fuerzas que se opongan con las armadas del Estado y las disidentes o grupos armados organizados, siempre que tengan un mando responsable y control territorial que les posibiliten la realización de operaciones militares sostenidas y concertadas, excluyéndose la hipótesis de presencia de tensiones y disturbios interiores. Sobre estos requisitos, diremos algunas palabras:

- Territorio. En teoría, no debe sobrepasar los límites que se reconocen al Estado para ejercer su dominio: esto es, aquellos que por tratados internacionales identifican las posibilidades de sujeción de sus habitantes a ciertas reglas, propias de una racionalidad jurídica, que lo faculta para exigir su cumplimiento mediante el ejercicio de una coacción, reputada legítima. Si los sobrepasa, el conflicto se convertirá en internacional.

- Contendientes. Al partir de la idea de un ejercicio de la autoridad, respaldado por el predominio de un Estado de Derecho, de entrada se facilitará la distinción entre quienes permanecen en las orillas de la defensa de ese orden y quienes se agrupan mediante el auxilio de la fuerza, para desconocerlo y por eso se les tilda de disidentes. En el fondo, se trata de un enfrentamiento por decidir quién tiene la razón, es decir, el po- 
der. En todo caso, se trata de una lid por establecer el imperio de su parecer, surgida entre los que se niegan a reconocer una autoridad válida y los que aspiran a seguir manteniéndola.

- Mando responsable. En seguimiento de claras pautas sociológicas, se precisa que como común denominador los integrantes de un grupo se aglutinen alrededor de un criterio que los unifique, lo cual implica, por lo menos, la adopción de un principio organizativo que se traduzca en el establecimiento de jerarquías, así éstas se aparten de los convencionalismos que distinguen las instituciones estatales. Es natural, entonces, que la repartición de labores definidas haga primar los papeles de supra y subordinación para obtener los mejores rendimientos. Así habrá quien mande y quien obedezca.

\section{Control sobre una zona física. Por lo pronto,} se ha erradicado de la pertenencia a este criterio a los conocidos como grupos itinerantes o nómadas, no sabemos si con acierto, en particular cuando ya resultan menos frecuentes los enfrentamientos cuerpo a cuerpo y que como estrategia de combate no es aconsejable la fácil localización del enemigo, lo cual en lugar de restarle poderío lo acrecienta.

Antes se había fundado la razón de ser de este requisito en la inexacta idea de que ello favorecía el desencadenamiento de operaciones sostenidas y concertadas, porque en relación con lo primero, es preferible un ataque intenso y devastador, lo cual dificulta en extremo las reacciones defensivas (el arma favorita del terrorismo, que no permite desligarlo en muchos eventos de su capacidad), que produce debilitamiento psi- cológico y sensación de impotencia, mientras que lo segundo no tiene necesariamente por qué relacionarse con la permanencia en un sitio determinado. Nos parece, con todo el respeto, que el Protocolo II confundió las exigencias para reconocer el "estado de beligerancia" con las propias de aceptar la contextura de un grupo como destinatario de las normas en mención, y que en el fondo estaba pensando su hacedor más en una guerra civil que en belicosidades graves, pero que no alcanzan ese rango. En lenguaje simple, no se pueden cotejar las condiciones que han hecho carrera como propias de la vida estatal con las que debería copar el grupo opositor, que se resisten a ser introducidas dentro de la redoma de un "miniestado".

De otra parte, si se estaba pensando en la capacidad de cuidar a los prisioneros o heridos, se está confundiendo para muchos efectos la entidad de la fuerza con posibilidades que no hacen parte de ese concepto. Se colige también que se describen las conductas de acción y de omisión y, desde otra consideración, algunas que corresponden a las matrices de crímenes de guerra que tocan con inobservancias de alguna magnitud ocasionadas por los combatientes, encasillables dentro de las diferentes violaciones a los usos y costumbres de la guerra, que en principio se extendían solamente a los conflictos internacionales, pero que poco a poco se han venido predicando de los internos, y a la de lesa humanidad, cuya esencia no se separa de la gravedad, basada en la causación de sufrimientos intensos o riesgos a la salud mental o física de la víctima, sea conectable a un ataque generalizado y sistemático, se dirija contra los miembros de la población civil y sea perpetrado por razones inscritas en el terreno de lo discriminatorio ra- 
cial, étnico, político, religioso o nacional ${ }^{19}$, lo cual no es característico sólo de tiempos de guerra, con lo que se deduce una fundamental distinción con los ilícitos que examinamos. Es más, nuestro Estatuto Criminal consagra en otros lugares el genocidio, la desaparición forzada y, acaso esbozado, el apartheid en su art.147.

Desde otro ángulo, se precisa que la imputación se construya merced a la correlación que se pueda establecer entre la calidad de combatiente, en desmedro del sujeto pasivo que se desprenda del contexto del tipo, con ocasión y desarrollo de un combate, lo que obligará al juez a establecer la permanencia o temporalidad de la previsión típica es decir, a apreciar con flexibilidad o dureza una condición que pese a ser objetiva en apariencia, será de muy difícil precisión en la práctica, por la diversidad de presupuestos que congregaría.

\section{BIBLIOGRAFÍA}

ALEXY, Robert. Tres escritos sobre los derechos fundamentales y la teoría de los principios. Bogotá: Externado. Carlos Bernal Pulido, 2003.

AMBOS, Kai. Temas del Derecho penal internacional. Bogotá: Externado. Fernando del Cacho y otros, 2001.

ARISTÓTELES. Gran ética. Buenos Aires: Aguilar. Francisco de P. Samaranch, 1961.

ASIMOV, Isaac. Las palabras y la historia. BarceIona: Laia. Rosa M. Padró, 1981.

BAURMANN, Michael. El mercado de la virtud. Barcelona: Gedisa. Eduardo Garzón Valdés, 1998.
BILBENY, Norbert. Aproximación a la ética. Bogotá: Ariel, 1992.

BOBBIO, Norberto y otros. Crisis de la democracia. Barcelona: Ariel. Jordi Marfá, 1985.

BOUTHOUL, Gastón. La guerra. Barcelona: OikosTau. Johanna Givanel, 1971.

CASAS, Bartolomé de Las. Obras completas. Madrid: Alianza, 1990.

CEPEDA, Manuel José. Los derechos fundamentales en la Constitución de 1991. Bogotá: Temis, 1992.

CHILDE V, Gordon. Qué sucedió en la historia. Buenos Aires: Siglo XX. 1956.

CORTINA, Adela. Hasta un pueblo de demonios. Madrid: Taurus, 1998.

DUNANT, Henri. Recuerdo de Solferino. Ginebra: Comité Internacional de la Cruz Roja. Sergio Moratiel Villa, 1982.

DURANT, Will. Nuestra civilización oriental. Buenos Aires: Sudamericana. C. A. Jordana, 1952.

GUZMÁN MORENO, Jorge. Breve historia de los derechos humanos. Bogotá, 2001.

HART, Herbert L. A. Entre utilidad y derechos. Bogotá: Externado. Everaldo Lamprea M., 2003.

IBÁÑEZ GUZMÁN, Augusto. “Delitos contra las personas y bienes protegidos por el D. I. H." En: Lecciones de D. P. Parte Especial. Bogotá: Externado, 2003. 19 Ver RAMELLI, Alejandro. «Personas y bienes protegidos por el D. I. H.» En: Lecciones de penal especial. Bogotá: Universidad Externado de
Colombia, 2003. pp 697 ss. 
JARAMILLO ORTIZ, Daniel. Las nuevas tendencias del D. I. en Ciencia Política. Bogotá: Tierra Firme, 1995.

MADRID-MALO GARIZÁBAL, Mario. "Derecho humanitario y reconocimiento de beligeranCia". En: D. I. H. en Colombia. Bogotá: TM Editores, 1998, T. II.

MARCUSE, Herbert. Ética de la revolución. 2a edición. Madrid: Taurus. Aurelio Álvarez, 1970.

MENÉNDEZ PIDAL, Ramón. El P. Las Casas y Vitoria. Madrid: Espasa Calpe, 1996.

OROZCO ABAD, Iván. Combatientes, rebeldes y terroristas. Bogotá: Temis, 1992.

PÉREZ-LUÑO, Antonio Enrique. La universalidad de Ios D. H. y el Estado constitucional. Bogotá: Externado, 2002.

RAMELLI ARTEAGA, Alejandro. "Personas y bienes protegidos por el D. I. H." En: Lecciones de D. P. Parte Especial. Bogotá,

El reconocimiento de beligerancia frente al conflicto armado colombiano. Bogotá: Externado, 2003.
ROTHSTEIN, Robert L. "Democracia, conflicto y desarrollo en el tercer mundo". En: Ciencia política. Bogotá: Tierra Firme, 1991.

SONTAG, Susan. Ante el dolor de los demás. Bogotá: Alfaguara, 2003.

SUANCES, Marco Manuel A. Max Scheler. Barcelona: Herder, 1976.

UPRIMMY YEPES, Rodrigo. "Sentido y aplicabilidad del D. I. H. en Colombia". En: D. I. H. en Colombia. Bogotá: T.M. Editores, 1998, T. II.

VALENCIA VILLA, Hernando. "Humanizar la guerra para negociar la paz". En: D. I. H. en CoIombia. Bogotá: T.M. Editores, 1998, T:Il.

VERDROSS, Alfred. Derecho internacional público. Madrid: Aguilar. Antonio Truyos y Serra, 1976.

VITORIA, Francisco de. Del Derecho de guerra. Madrid: Espasa Calpe, 1962.

ZAFFARONI, Eugenio Raúl. Criminología. Bogotá: Temis, 1988.

ZULETA, Estanislao. Colombia: violencia y democracia y D. H. Bogotá: Altamir, 1991. 